\title{
"Geografizando" o mundo dos sentidos dos jovens da Igreja Assembleia de Deus
}

\author{
"Geografizando" el mundo de los sentidos de los Jóvenes de la \\ Iglesia Asamblea de Diós
}

\author{
Geographying' the world of the senses of youth in the \\ Assembly of God Church
}

\author{
Dalvani Fernandes \\ dalvani.fernandes@gmail.com \\ Instituto Federal do Paraná
}

\begin{abstract}
Resumo: A Geografia, engajada no campo das Ciências Humanas, há longos anos vem construindo um arcabouço teórico que nos auxilia a refletir sobre a complexidade do espaço social. No entanto, o pensamento geográfico é ainda pouco explorado na compreensão de fenômenos como a religião e a juventude. É a respeito dessa articulação teórica que o presente trabalho procura contribuir, na intenção de apresentar uma "geografização" do mundo dos sentidos. Para esse desafio utilizamos a filosofia das Formas Simbólicas de Cassirer, procurando, a partir dela, entender a religião enquanto formadora de sentido para a realidade da juventude evangélica. Utilizamos a metodologia de observação participante, envolvendo-nos no mundo linguístico construído pelo discurso da Igreja Evangélica Pentecostal Assembleia de Deus, na cidade de Guarapuava, PR. Partindo do material empírico, obtido nas observações, procuramos identificar quais espacialidades são produzidas, a partir do discurso religioso, nas vidas desses jovens.
\end{abstract}

Palavras-Chave: Epistemologia. Religião. Juventude. Formas Simbólicas. Espacialidades.

Resumen: La Geografía se configura como disciplina del área de las Ciencias Humanas y en el largo de los años viene construyendo una estructura teórica que nos ayuda a reflexionar sobre la complejidad del espacio social. Todavía, el pensamiento geográfico ha poco explotado la comprensión del fenómeno religión y juventud. Intentando contribuir para la comprensión de la articulación las referidas dimensiones, este trabajo busca teorizar sobre la "geografización" del mundo de los sentidos. Para ese desafío utilizamos la filosofía de las Formas Simbólicas de Cassirer. Buscando a partir de ello, comprender la religión en la formación de un sentido para la realidad de la juventud evangélica. Utilizamos el método de observación participante envolviéndonos en el mundo lingüístico construido por el discurso de la Iglesia Evangélica Pentecostal Asemblea de Dios, en la ciudad de Guarapuava, PR. Partiendo del lo empírico, obtenido, buscamos la identificación de las espacialidades que están siendo producidas desde el discurso religioso, en la vida de esos jóvenes.

Palabras-clave: Epistemología. Religion. Juventud. Formas Simbólicas. Espacialidades. 


\begin{abstract}
Over many years the area of geography that is engaged with human sciences has been building a theoretical framework that helps to reflect on the complexity of social space. However, geographical thought is still under- explored to interpret phenomena such as religion and youth. This paper seeks to contribute to this discussion by presenting a 'geographying' of the world of the senses. For this challenge we use Cassirer's philosophy of symbolic forms to understand religion as forming sense for the reality of evangelical youth. We use the methodology of participant observation and we engage in the linguistic world constructed by the discourse of the Assembly of God, Evangelical Pentecostal Church, in Guarapuava,PR. Based on empirical data obtained in the observations, we seek to identify which spatialities are produced from the religious discourse in the lives of these young people.
\end{abstract}

Keywords: Epistemology. Religion. Youth. Symbolic form. Spatialities.

\title{
INTRODUÇÃO
}

O presente trabalho trata da relação entre Geografia, juventude e religião. Dentre as muitas possibilidades de interpretar o fenômeno religioso, escolhemos a perspectiva da religião enquanto fornecedora de sentido para a vida, um meio de organizar o mundo plasmando a realidade de significado. Parte-se do suposto que, desde que nos conhecemos e nos encontramos no mundo, passamos a desenvolver os atos de "conhecer" e de dar "sentido" à realidade. (BERGER; LUCKMANN, 1997).

Para Cassirer (2001), toda cultura é linguagem, por essa razão: Religião, Mito, Arte e Ciência são consideradas Formas Simbólicas, que no seu sentido cultural se equivalem, pois cada uma possui sua maneira específica de objetivar o mundo. Eis o caminho teórico que trilhamos para a compreensão do fenômeno religioso.

$\mathrm{O}$ ato de dar sentido ao mundo é explicado poeticamente por Rubem Alves. Da mesma forma que os animais lançam para o mundo a ordem interiorizada em seus organismos (a aranha, a teia; a abelha, a colmeia), o ser humano exterioriza suas redes simbólico-religiosas em forma de melodias que se expandem sobre o universo inteiro. Assim, vão aos "confins do tempo e aos confins do espaço, na esperança de que céus e terra sejam portadores de seus valores. O que está em jogo é a ordem". (ALVES, 1981, p. 26). O ser humano tem necessidade de viver em um mundo que faça sentido, o seu mundo. Sendo assim, o homo religiosus procura dar sentido à realidade através de representações e símbolos religiosos que ordenem o caos em que vive.

Concordando com a tese de que aqueles que habitam um mundo ordenado e carregado de sentido gozam de um senso de ordem interna - integração, unidade, direção - e sentem-se efetivamente mais fortes para viver, teremos então diante de nós a efetividade e o poder dos símbolos (SILVA; GIL FILHO, 2009). Nesse viés, a obra de Cassirer oferece algumas contribuições para a Geografia da Religião, possibilitando a articulação de conceitos, como: Formas Simbólicas, espacialização e espacialidades. Entendemos por espacialidade uma dimensão no fenômeno que se espacializa, não sendo necessariamente uma manifestação material; está ligada a uma visão de mundo constituída a partir de um 
discurso. As espacialidades são constituídas a partir dos sentidos com que o sujeito plasma sua realidade, "geografizar" esse mundo dos sentidos é mergulhar em um universo fenomenológico buscando a compreensão da lógica da organização do real - lógica essa que se dá através das Formas Simbólicas.

O fenômeno religioso ultrapassa o espaço material, constituindo outros espaços religiosos (espacialidades), por meio da sociabilidade juvenil. Nesse sentido, nossa proposta é explorar dois importantes elementos que necessitam de aprofundamento no campo da Geografia: a religião e as juventudes. A relação entre religião, espaço e juventudes abre um campo de abordagem amplo e diversificado. Acreditamos que uma das contribuições desse trabalho esteja na consideração da sociabilidade envolvida na vivência da fé no cotidiano dos jovens, possibilitando, assim, a compreensão do espaço de forma dinâmica e para além da materialidade simples e evidente.

Entendemos que é nesse ponto que podemos contribuir com uma discussão epistemológica, pois estamos diante de uma Geografia que se propõe a olhar para os sujeitos e compreender seus mundos simbólicos, o que tentaremos discutir aqui, ainda que de maneira incipiente, propondo uma geografização dos sentidos a partir da filosofia cassireriana.

Para tanto, colaremos em tela os resultados de nossa pesquisa de mestrado, defendida em fevereiro de 2012, na qual nos propusemos a compreender os sentidos gerados pelo mundo simbólico (Forma Simbólica Religião) na vida de jovens que frequentam/ frequentaram a Igreja Evangélica Pentecostal Assembleia de Deus, em Guarapuava, PR (FERNANDES, 2012).

\section{RELIGIÃO - UMA FORMA SIMBÓLICA}

O estudo das Formas Simbólicas em Cassirer vem sendo apropriado pela Geografia da Religião (GIL FILHO, 2007; 2008; 2009; 2010; 2011), na busca de uma construção da teoria do Homem frente ao fenômeno religioso; considerando-se que, para Cassirer (2005), o ser humano é interpretado como um ser symbolicum, que não vive somente no mundo dos fatos, mas, antes, em um mundo simbólico.

Sendo assim, pensamos o espaço através da atuação das Formas Simbólicas, conceito que pode ser entendido como: energia do espírito, em que um conteúdo espiritual do significado está vinculado a um signo sensível concreto, atribuído interiormente (CASSIRER, 2001). Em outras palavras, são os aparatos artificiais da nossa consciência (espírito linguístico) que projetam o conhecimento sobre o mundo, conformando (dando sentido a) a realidade.

O conceito de Forma Simbólica pode ser utilizado na tarefa de espacialização da religião. Para Cassirer, somos homens simbólicos em nossa forma de pensar, através da linguagem construímos um mundo de símbolos - um mundo cultural - é nesse mundo "artificial" no qual o Homem vive. Existem vários "mundos" que são conformados a partir de diferentes perspectivas, assim temos as Formas Simbólicas: Mito, Arte, Religião, Ciência, entre outros (CASSIRER, 2005). A Geografia, partindo do espaço da cultura, 
analisa os espaços de ação formados por essas Formas Simbólicas; daí surge a possibilidade de análise do espaço de ação do "mundo jovem", formado a partir da Forma Simbólica Religião. (FERNANDES, 2011).

Para Cassirer, o ser humano, vivendo em um sistema simbólico, "não vive apenas em uma realidade mais ampla; vive, pode-se dizer, em uma nova dimensão da realidade" (2005, p. 48). Não se encontra mais em um universo físico, agora vive em um universo simbólico, num mundo cultural construído pela Linguagem, Mito, Arte, Ciência e Religião.

\section{APRESENTANDO A PESQUISA}

De janeiro a abril de 2011, participamos dos cultos na Assembleia de Deus (ADD), no seu templo sede, localizado no centro da cidade de Guarapuava, estado do Paraná. Não podemos afirmar que essa realidade seja a mesma em outros contextos, o que apresentamos diz respeito a esse espaço-tempo.

Os objetivos da pesquisa foram: 1) compreender os sentidos que são gerados na construção da realidade da juventude evangélica através do discurso da Igreja Evangélica Assembleia de Deus; 2) identificar as formas de ser jovem na Igreja em foco; 3) observar quais espacialidades são construídas a partir da sociabilidade de uma juventude evangélica.

Nossas observações, matizadas pelo prisma do conceito de habitus (BOURDIEU, 1998), nos levaram a um resultado que elucida diferentes "categorias" da juventude evangélica.

a) Jovem veterano: aquele que é evangélico "de berço", ou então se converteu quando ainda era criança. A partir da experiência desse jovem construímos a ideia de espacialidade resignada, formada por uma entrega ao universo religioso, uma submissão sem questionamentos, que reforça o discurso religioso para além da espacialidade concreta do templo. Uma espacialidade assim pensada pode ser expressa na busca desse jovem pelo sentimento de paz em sua vida, o que exige dele a manutenção constante de um religare que impõe a submissão a Deus e às autoridades religiosas.

b) Jovem desviado: jovem que foi batizado na Igreja e hoje está desviado (afastado) da comunidade religiosa, mas esporadicamente aparece nos cultos. Notamos que os conflitos existenciais vividos pelo jovem desviado podem ser expressos na ideia de espacialidade híbrida. O termo híbrido remete a uma mistura maleável, uma fusão entre dois elementos diferentes, neste caso o discurso religioso e a cultura juvenil representada pela ideia de "mundo" ${ }^{1}$. Conforma, assim, uma relação social e espacial onde elementos "mundanos" e religiosos se encontram, e sua importância tem pesos diferentes dependendo da situação em que o sujeito se encontra. É uma espacialidade permeável, mais aberta a novas experiências. Ser um desviado da Igreja é declarar independência.

1 Salientamos que a ideia de mundo, quando contraposta a Igreja/Religião, procura expressar tudo aquilo que é a não-religião, o não-sagrado. 
c) Jovem novo-convertido: aquele que se batizou há pouco tempo. O novo- convertido ainda não comunga da linguagem religiosa da sua nova comunidade, ele "não enuncia pensamentos. Ele canta sentimentos" (ALVES, 2005, p. 85). Sua forma de ser nos leva a refletir sobre uma possível espacialidade intermediária. Isto porque ela expressa uma passagem do aspecto místico (caráter mais expressivo, ligado às emoções) para o racional (caráter mais representativo, ligado a uma determinada ordem lógica) da religião. Esse trajeto não é linear, no entanto; para o jovem que está iniciando sua caminhada na Igreja, parece-nos que esse percurso é bem demarcado entre a fronteira do sentir e do pensar.

Partindo desses sujeitos realizamos nossa fenomenologia cassireriana, buscando uma hermenêutica que revelasse os sentidos fornecidos pela religião para cada "categoria" da juventude evangélica, bem como identificar as espacialidades que se conformam a partir da apropriação do discurso religioso nesses três diferentes modos de se viver a religião.

Nesse contexto, entendemos que a abordagem etnográfica, partindo das ideias de habitus religioso, representações e Formas Simbólicas, nos ajudaram a entender como a juventude evangélica se relaciona com o caráter sagrado da religião. Em síntese, a pesquisa procurou compreender, a partir do discurso da Igreja, alguns dos múltiplos sentidos que permeiam a realidade da juventude evangélica pentecostal.

\section{METODOLOGIA}

Interagimos com a mocidade evangélica que lá se congrega, participamos de seus cultos, reuniões e encontros. Visitamos alguns jovens em suas casas, saímos para lanchonetes e, algumas vezes, ficamos durante as madrugadas conversando - todos esses episódios facilitaram a relação entre pesquisador e pesquisado -, e assim tivemos acesso a muitas histórias de vida e depoimentos que foram registrados em nossa pesquisa. Partindo da metodologia de observação participante, registramos em nosso diário de campo quarenta encontros. Os encontros aconteciam na formalidade do culto da Igreja, a partir de lá marcávamos de nos encontrar em outros lugares como praça, ruas e mesmo na casa dos jovens assembleianos. Dessas experiências extraímos algumas anotações para melhor ilustrar o pensamento assembleiano.

Nossa pesquisa de campo se apoiou nos pressupostos qualitativos da observação participante. Conforme aponta Turra Neto (2004a), na Geografia essa metodologia pode ser uma ferramenta preciosa quando se tem no centro da análise fenômenos culturais engendrados pelo ser humano. Participar do universo simbólico de um determinado grupo permite que vejamos o sentido dos significados a partir da perspectiva dos que vivem e comungam daqueles símbolos. É uma visão de dentro para fora da comunidade.

Lüdke e André (1986, p. 26), discutindo o uso da observação participante, afirmam que ela é um método que permite que o observador chegue mais perto da "perspectiva dos sujeitos", um importante alvo nas abordagens qualitativas. O observador como 
participante, segundo as autoras, deve, desde o início, revelar ao grupo pesquisado a sua identidade de pesquisador e os objetivos do seu estudo. Nessa posição, o pesquisador pode ter acesso a uma gama variada de informações, até mesmo confidenciais, pedindo cooperação ao grupo. A pesquisa, nesse sentido, é tecida a "quatro mãos", tanto pelo pesquisador como pelo seu "sujeito-objeto". O pesquisador influencia o universo que observa, há uma troca de experiência gerada pelo convívio, por isso ele também é influenciado.

Fica então uma questão no ar: os dados do trabalho de campo merecem confiabilidade? Baseado em Becker (1999), Turra Neto (2004b, p. 92) defende que a resposta é 'sim' - por conta de dois fatores:

1) as pessoas são obrigadas a agir tal como se o pesquisador não estivesse ali, pois estão submetidas às restrições sociais. Assim, as pessoas têm papéis no grupo a cumprir e a obrigação com o grupo é mais forte que a inibição na presença do observador;

2) o(a) pesquisador(a) coleta muitos dados e passa longo tempo no campo, o suficiente para testar várias vezes suas conclusões. Neste sentido, há múltiplas evidências de que as conclusões não estão baseadas em fatos efêmeros.

Adotamos ainda como metodologia auxiliar a entrevista semi-estruturada, para a qual seis jovens (cinco homens e uma mulher) foram convidados a falar sua história de vida e o envolvimento com a religião e a Igreja; desses diálogos três foram escolhidos e trabalhados mais detalhadamente, cada um representando categorias diferentes dentro da Igreja. As entrevistas foram gravadas, sendo que cada jovem assinou um termo de consentimento. Além dessas entrevistas, ouvimos três adultos, representados pela figura do pastor presidente e pastor vice-presidente da Igreja e um membro que congrega nessa instituição há mais de vinte anos. A leitura de obras² publicadas pela própria Assembleia de Deus também fez parte de nossa metodologia e nos ajudou a compreender o discurso da Igreja.

É preciso dizer ainda que ouve outro desafio, aquele que surge no pós-campo. Como transpor a dimensão dialógica da pesquisa de campo para o texto? É possível conhecer a verdade dos fatos, ou simplesmente fazemos interpretações sobre eles? Sendo interpretações, poderíamos dizer que são limitadas e parciais e, por esse motivo, contestáveis?

Em busca de respostas, Turra Neto (2008, p. 373) argumenta que a existência de um objeto não pode ser separada da trama linguística que o descreve, em suas palavras: “[...] aquilo que o discurso científico diz sobre determinado aspecto da realidade está envolvido no processo de produção desta própria realidade, não só enquanto tal, mas também como objeto científico".

O mesmo sentido assume o pensar de Cassirer (2006), segundo o qual passa despercebido por todos nós o fato de que todo conhecer teórico parte de um mundo já lapidado pela linguagem, desta forma todo aquele que se dedica ao pensar convive com objetos exclusivamente ao modo como a linguagem lhos apresenta. Visto por esse viés,

2 Focamos o material didático da escola dominical: as revistas "Lições Bíblicas" (2011a; 2011b); e em livros publicados pela própria instituição através da CPAD - Casa Publicadora da Assembleia de Deus. 
toda a teoria lógica, que cria um conceito a partir de uma abstração generalizadora, perde sua serventia. Tal abstração consiste na escolha de determinadas características, que já são de antemão dadas pela linguagem. Em outras palavras, seguindo esse raciocínio, é um equívoco achar que teorias científicas ou conceitos derivados descobrem a realidade. Erro também pensar que o real assim descrito é uma entidade separada do sujeito que o escreveu.

Entendendo dessa forma, que nossa proposta não é explicar a realidade, colocamonos de uma maneira mais humilde perante a complexidade observada. Nossa intenção é compreender, no sentido fenomenológico ${ }^{3}$, como a realidade evangélica funciona, levando em consideração que a Forma Simbólica Religião se encontra no mesmo nível que a Ciência quando a questão é dar sentido ao mundo.

A Igreja ADD nos revela um universo construído para ser partilhado. A religião socializa, e como toda base de socialização, ela oferece uma verdade. Socializar na religião é aprender e dividir a verdade que ela oferece (ALVES, [1979] 2005).

Cassirer (2006) já nos lembra que antes de qualquer trabalho intelectual de conceber e compreender fenômenos é necessário transformar o mundo das impressões sensíveis em um mundo espiritual, um mundo de representações e significações. Nesse sentido é que vemos nosso trabalho de campo como um esforço em compreender de que maneira o crente transforma o mundo das impressões em um mundo de representações e significações cristãs, através da doutrina pentecostal da Igreja em foco.

\title{
RESULTADOS E DISCUSSÃO: APRESENTANDO A IGREJA ASSEMBLEIA DE DEUS E SUA JUVENTUDE
}

\begin{abstract}
“Depois disso, acontecerá que derramarei o meu Espírito sobre todo ser vivo: vossos filhos e vossas filhas profetizarão; vossos anciões terão sonhos, e vossos jovens terão visões"
\end{abstract}

A epígrafe acima representa bem o limiar do mundo pentecostal assembleiano. Um mundo onde se vive uma relação com o sobrenatural, onde há milagres, dons e profecias. Um mundo tecido por uma teia simbólica cuja matéria-prima provém do Livro Sagrado onde se encontram "as palavras de Deus".

A ADD está presente em toda a cidade de Guarapuava. O templo sede, foco de nossas observações, localizado no centro, em frente ao $26^{\circ}$ G.A.C. (Exército), também recebe jovens que moram em bairros próximos, como Santa Cruz, Batel e Bairro dos Estados, propiciando uma grande diversidade cultural juvenil.

3 De acordo com Japiassú e Marcondes (1996, p. 47), compreensão passa a ser definida com a fenomenologia como "um mundo de conhecimento predominantemente interpretativo, por oposição ao modo propriamente científico, que é o da explicação". Para os autores - explicar - remete a um modo de conhecimento analítico e discursivo "procedendo por decomposições e reconstrução de conceitos." Compreender, por sua vez, "é um modo de conhecimento de ordem intuitiva e sintética." 
Convivi com essa juventude, ou para usar o vocabulário assembleiano, com essa mocidade, de janeiro a abril de 2011, de maneira intensa, e nos outros meses do ano com visitas esporádicas. A mocidade evangélica é plural, constituída de homens e mulheres na faixa ${ }^{4}$ dos 14 aos 39 anos $^{5}$, todos moram em Guarapuava, sendo que 68\% em bairros próximos ao centro e 32\% em residências no centro; e 32\% são jovens que tocam algum tipo de instrumento musical. A maioria trabalha e/ou estuda (76\%); dentre os que estudam, 40\% cursa ou já cursou o ensino superior. Alguns são casados (32\%), e a média é de um filho por casal. Interessante observar que $40 \%$ dos jovens dizem ser evangélicos da Assembleia desde que nasceram; 40\% afirmam que estão na Igreja há mais de três anos; e 20\% há menos de três anos. Dá para notar que a Igreja trabalha pela manutenção de sua juventude.

Há vários grupos dentro do conjunto de jovens que frequentam a Igreja. Existem aqueles que estão ligados à música (na maioria, homens) e aqueles ligados à dança (na maioria, mulheres). Também há o grupo de líderes dos jovens, formado por jovens mais velhos. Além da clara divisão entre os sexos, homens de um lado e mulheres de outro. Fora isso, é possível encontrar pequenos grupos de interesse como amizade, paqueras, estudo, trabalho, etc. Uma grande "galera" de amigos, conhecidos, e gente nova que vai se agregando aos poucos, dando os contornos de uma espacialidade social que se vive entre os muros da Igreja.

As redes sociais aparecem ligadas a essa espacialidade, que está diretamente vinculada à sociabilidade juvenil religiosa. A partir dos amigos, novas conexões são possíveis, e novos convites para conhecerem outras Igrejas ou viverem experiências fora delas são feitos. Apesar de o discurso religioso defender uma vivência de comunidade entre iguais, a escolha das redes de sociabilidade é individual e subjetiva. Carrano (2002) nos lembra que podemos encontrar redes múltiplas quando o sujeito estabelece vários vínculos (caso do jovem desviado); e redes simples, aquelas que se caracterizam por um único vínculo dominante (caso do jovem veterano).

Para os jovens que estão, como eles mesmos dizem, "firmes na fé" - participantes de uma rede simples - existem ocupações autoimpostas em seu tempo livre para que efetuem uma sociabilidade dentro da Igreja. Estas ocupações não são, necessariamente, relativas ao lazer. Ocupam boa parte do tempo livre com atividades como: música e dança (ensaios para o grupo de louvor), teatro, estudos bíblicos, vigílias, entre outras. Tais atividades, conforme observou Carrano (2002, p.79), não são destituídas de ludicidade, pois "a perspectiva da diversão está presente na própria forma de proposição das atividades".

A música, a dança, os cultos temáticos (culto anos 60, por exemplo) atuam como elementos importantes no processo de coesão e motivação do grupo de jovens da Igreja. Esses espaços também cumprem com o papel de propiciar ambientes de diversão dentro da Igreja, pois assim há menos chances de os jovens procurarem espaços "mundanos"

4 Essas informações foram coletadas com aplicação de 25 questionários no qual foram levantadas questões para saber idade, ocupação, estado civil, escolaridade, endereço e trabalho.

5 As idades mais avançadas, 32 para mulher e 39 para homem, dizem respeito aos casais da Igreja responsáveis pela liderança dos jovens. Entendemos que como eles estão sempre presentes do grupo, também fazem parte da mocidade evangélica. Optamos por não delimitar a juventude pela idade, pois entendemos que a condição juvenil vivida no seio da Igreja não é delimitada pela faixa etária. 
para esse tipo de satisfação. Dessa forma, observamos um paradoxo, pois nota-se que há uma abertura de espaço dentro da Igreja para o jovem, abertura essa que se torna necessária justamente para o jovem não "fugir".

\section{A GEOGRAFIZAÇÃO DOS SENTIDOS DA JUVENTUDE EVANGÉLICA}

Após a imersão cultural no universo da Igreja, procuramos então organizar nossas reflexões, buscando possíveis interpretações para o universo juvenil evangélico. Daí surgiu a necessidade de uma geografização dos sentidos dessa juventude, isto é, a busca por uma compreensão de cunho espacial para a ação da Forma Simbólica Religião. Aceitando o desafio, encontramos um terreno estável no conceito de habitus ${ }^{6}$ para construirmos nossa interpretação da juventude assembleiana.

Para isso elaboramos três categorias ideais, focadas na experiência pessoal dos jovens com o sagrado.

\begin{tabular}{|c|c|c|}
\multicolumn{2}{|c|}{ Quadro 01 - Categorias Ideais Da Juventude Evangélica } \\
\hline \multicolumn{2}{|c|}{ Juventude Evangélica da Assembleia de Deus } \\
\hline Veteranos & Novos-convertidos & Desviados \\
\hline $\begin{array}{c}\text { Esse grupo é formado por jovens que } \\
\text { nasceram em berço evangélico, ou } \\
\text { então, são membros há mais de 10 } \\
\text { anos. Já incorporaram o discurso e a } \\
\text { identidade evangélica. }\end{array}$ & $\begin{array}{c}\text { Grupo formado pelos jovens que } \\
\text { há menos de 1 ano participam da } \\
\text { comunidade evangélica. Em geral } \\
\text { eram católicas e se converteram ao } \\
\text { protestantismo pentecostal. }\end{array}$ & $\begin{array}{c}\text { Seriam os jovens que já estiveram } \\
\text { algum motivo hoje estão no "mundo mo } \\
\text { podendo voltar a qualquer momento } \\
\text { para Igreja. }\end{array}$ \\
\hline
\end{tabular}

Org: FERNANDES, D. 2011.

Diante desse quadro procuramos entrevistar jovens que representassem cada uma das categorias. A entrevista na verdade foi uma conversa gravada, durante a qual os jovens contaram suas histórias de vida, suas dificuldades, sonhos e desejos.

\section{O VETERANO}

Categoria criada observando-se a interação dos jovens dentro da comunidade religiosa. A espacialidade expressa pelo veterano, como aprofundaremos mais tarde, revela uma identidade assembleiana interiorizada, partindo de uma relação emocional profunda com o sagrado, construída ao longo de um processo sócio-histórico. Tive a impressão que alguns jovens dizem viver em plena harmonia com o discurso expresso pela ADD, de tal modo que o discurso marca seus corpos, molda seu estilo de vestir e recheia seu vocabulário com palavras utilizadas em cultos. Até mesmo sonhos e projetos de vida se espacializam na vida desses jovens partindo das referências propostas pela

6 O conceito de habitus (BOURDIEU, 1998) nos ajudou em campo a observar as diferenças que os jovens apresentam dentro da comunidade religiosa. Apesar de haver um habitus religioso comum a todos os crentes (oração, estudo da Bíblia, participação nos cultos, uso de roupas discretas), há variações que se apresentam de maneiras diversas. Dessas variantes recortamos três grupos que mais nos chamaram atenção, os quais são analisados no trabalho. 
Igreja. O estilo de vida do jovem veterano convida-nos à ideia de uma espacialidade do ethos, ou seja, a maneira como o espaço é conformado pela vivência desse jovem é permeada por uma cultura, um habitus e uma "ética pentecostal" que dá sentido ao seu mundo.

Os tipos ideais que foram apresentados revelam uma vivência ligada diretamente à ideologia pentecostal, ao aspecto místico e sagrado dessa forma de vivência da religião cristã. No que concerne à mística, observamos, no caso do jovem veterano, uma relação em que se acredita que os dons do Espírito Santo são manifestados; nesse impulso há uma busca em desenvolvê-los de modo a aplicá-los em seu ministério e se aprofundar em sua fé. Criamos a figura abaixo com base no depoimento do jovem veterano.

Figura 01 - Jovem veterano

DESTAQUE DOS FATOS MAIS SIGNIFICATIVOS NA VIDA DO JOVEM VETERANO

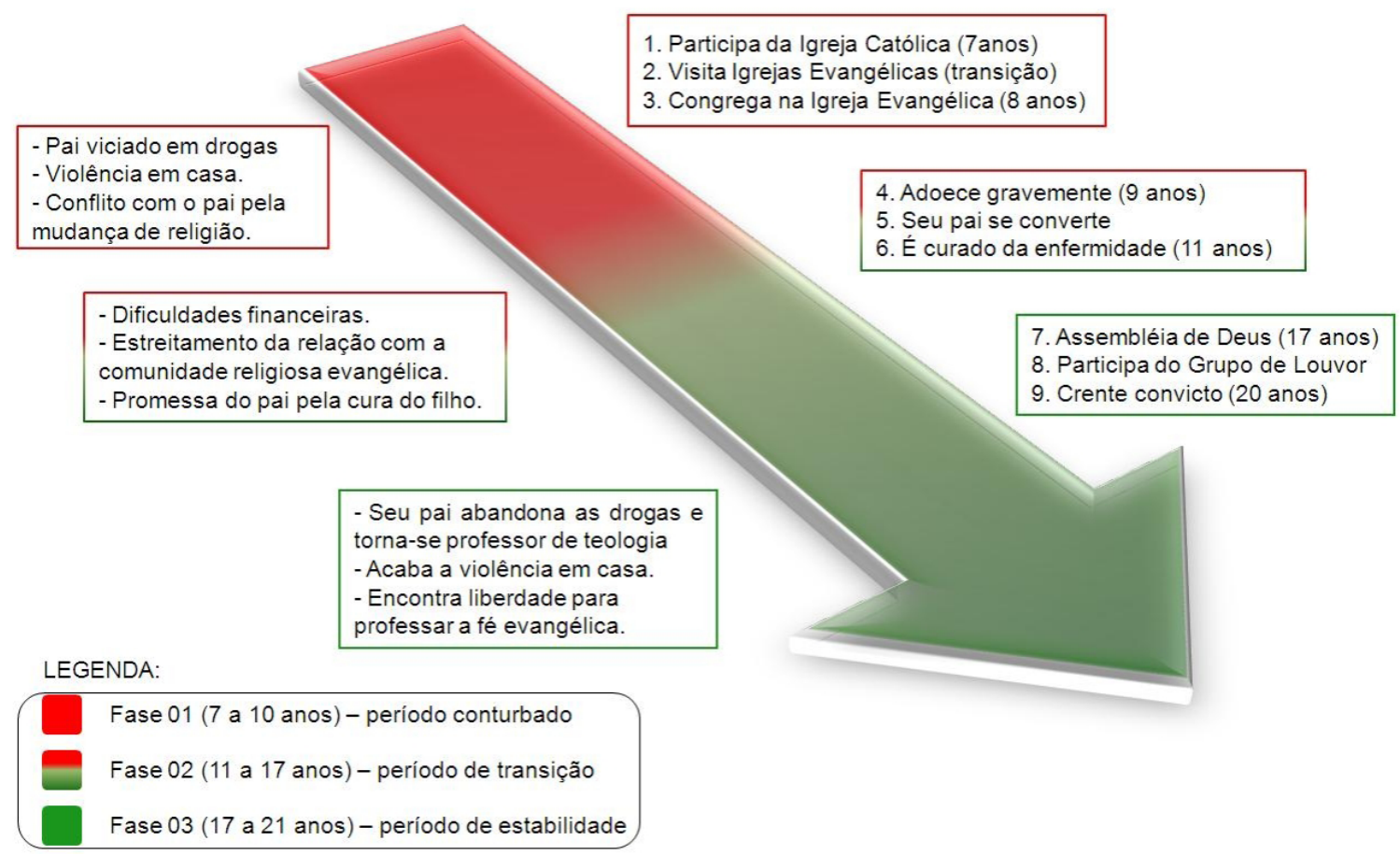

Org: FERNANDES, D. 2011

É possível perceber que a vida do jovem muda radicalmente, e que a família, principalmente seu pai, tem grande importância nessa transição. A figura da seta acima é linear, pois a intenção é trazer a ideia da passagem do tempo, que é dividido pelas idades do jovem. Também remete a um "caminho reto", tendo em vista que o jovem, ao ter consciência de sua religiosidade, optou por vivê-la em uma igreja evangélica, mantendo-se nesse caminho até então, sem desvios.

\section{O DESVIADO}

O sentido de desviado pode ser entendido pela Igreja de modo pejorativo, como sinônimo de apostasia. De acordo com Renovato (2007, p.16), uma das maneiras de se 
observar a apostasia é através dos "manifestos comportamentos contrários à santidade requerida por Deus em sua palavra." O jovem desviado, pelo que foi observado, é justamente esse que deixa de percorrer os "caminhos doutrinários" e passa a adotar comportamentos "contrários à santidade", conforme a doutrina que a Igreja ensina. Esse sujeito vive um desencontro/desencanto com o sagrado institucionalizado e, sendo ele até então um membro da Igreja, essa ruptura ganha uma dimensão geográfica em sua vida, novas espacialidades são conformadas de forma que sua religiosidade possa ser vivida, mesmo que desligada da instituição religiosa.

O mapa mental que montamos (figura 02) para melhor compreender a trajetória de vida do jovem desviado é um dos mais interessantes, pois podemos visualizar que o desvio do jovem é um movimento cíclico, ligado diretamente a seus anseios existenciais, e que se reflete diretamente no espaço através de suas ações e opções pessoais. O caminho "reto", da Igreja, se diferencia dos múltiplos caminhos do "mundo", explicamos: o primeiro se refere a um conjunto de ações baseados em um ethos religioso fundamentado na interpretação oficial da Igreja sobre a Bíblia; o segundo, as outras possibilidades que se abrem ao jovem estando fora da Igreja. Diferente da figura criada para o veterano, essa se pauta mais no espaço do que no tempo. Esse jovem, apesar de escolher amigos, ações, espaços diferentes dos oferecidos pela religião, carrega em si o discurso da Igreja, fazendo com que sua trajetória seja representada por idas e vindas da Igreja para o "mundo" e vice-versa.

Figura 02 - Jovem Desviado

\section{DESTAQUE DOS FATOS MAIS SIGNIFICATIVOS NA VIDA DO JOVEM DESVIADO}

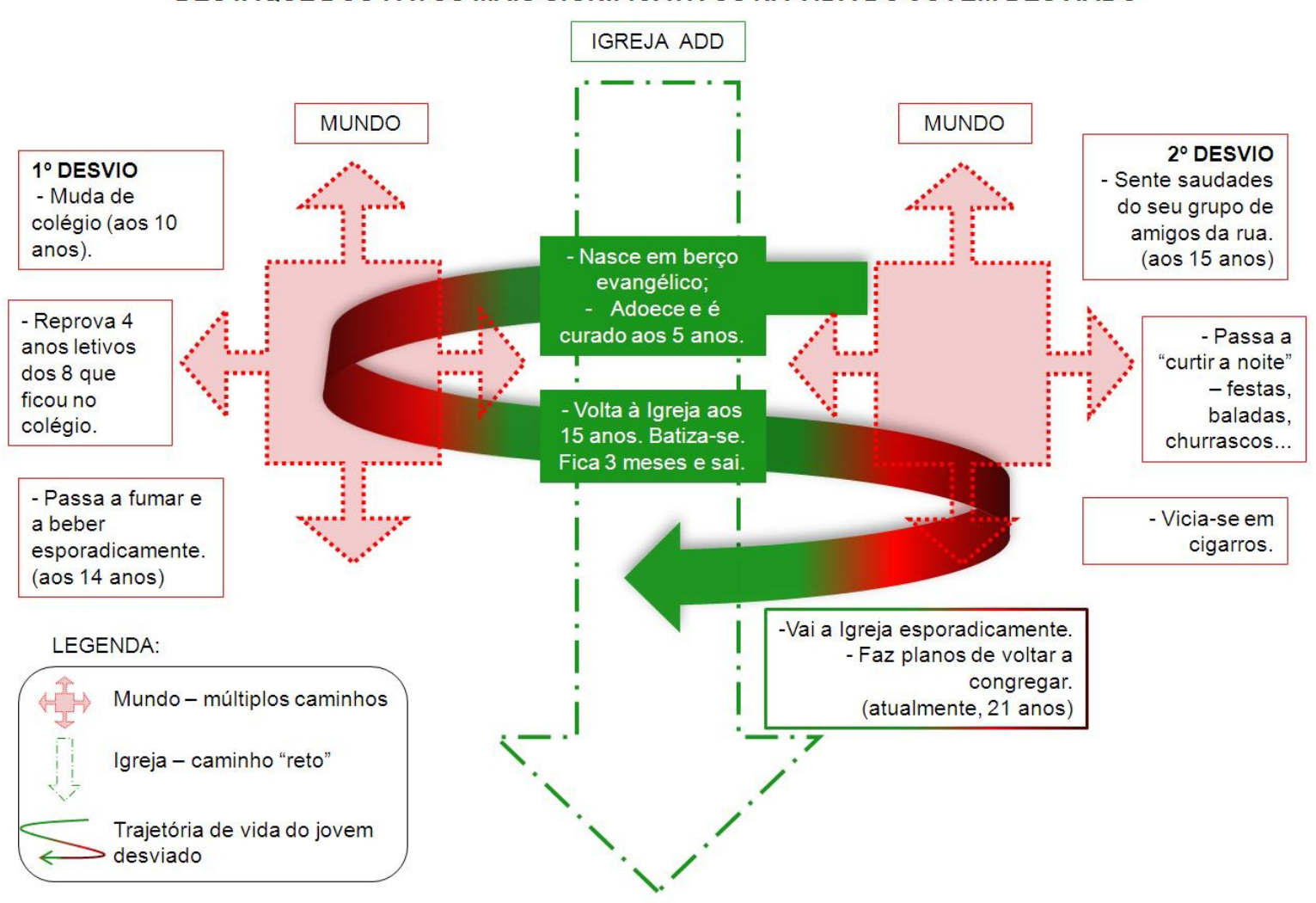

Org: FERNANDES, D. 2011. 


\section{O NOVO-CONVERTIDO}

Existe um trânsito religioso onde se observa um fluxo de jovens que visitam a congregação sede da Assembleia. Alguns visitantes são de outras congregações da própria ADD, de outras denominações cristãs ou então jovens que ainda não optaram por uma religião. Geralmente são convidados pelos jovens que ali já congregam. Fruto dessas visitas ocorre de alguns/algumas jovens optarem por uma conversão/re-conversão. Nesse cenário, a participação dos colegas conta muito, pois os convites para conhecer uma nova Igreja partem dos grupos de amigos, em geral da escola ou do trabalho. A espacialidade social, marcada pelas redes de sociabilidade dos/as jovens, surge como um mecanismo de evangelismo essencial para a renovação da membresia juvenil da Igreja.

Para os jovens que buscam uma experiência espiritual, o culto pentecostal é muito atraente. Um universo é falado, cantado, lido, chorado, profetizado pelos assembleianos. Essa postura mística, apresentada pelos relatos de milagres, é valorizada ainda mais durante as orações que trazem fala em línguas estranhas, curas, exorcismos e louvores embebidos de alto teor emocional.

Observamos que diante desse fascínio, o/a jovem que até então não conhece o mundo pentecostal, coloca-se diante dessa realidade de duas formas: a) sente medo e evita o desconhecido; b) busca sentir essa experiência, podendo depois viver a doutrina pentecostal. Em nosso trabalho buscamos conhecer e aprofundar os sentidos dados à realidade a partir do jovem que opta por mergulhar no invisível, tornando-se assim um novo-convertido da Igreja Assembleia de Deus. A figura abaixo ilustra um breve trecho da trajetória desse jovem, até se encontrar com a ADD.

Figura 03 - Jovem Novo-Convertido

DESTAQUE DOS FATOS MAIS SIGNIFICATIVOS NA VIDA DO JOVEM NOVO-CONVERTIDO

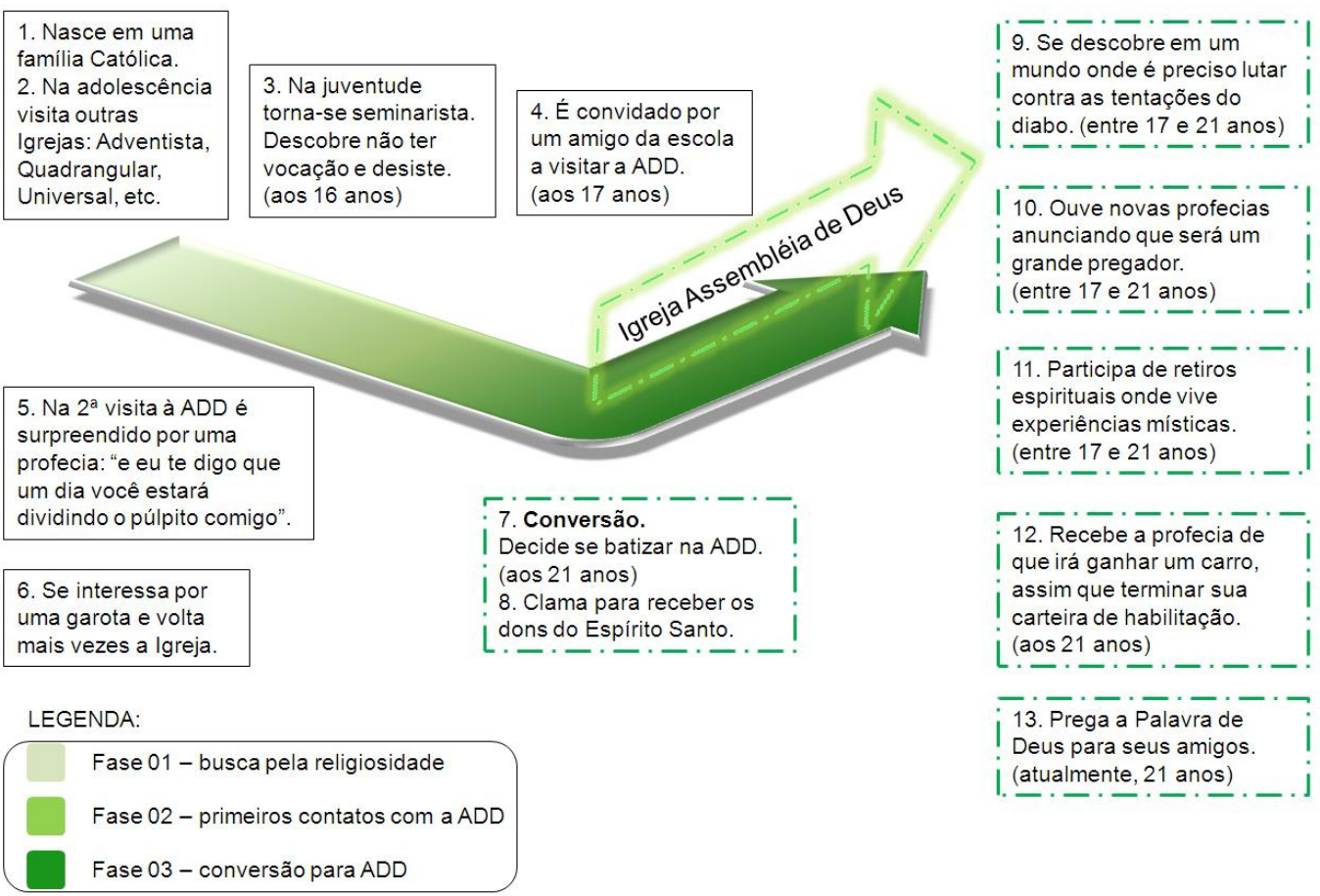

Org: FERNANDES, D. 2011. 
Utilizamos a cor verde porque entendemos que não houve no depoimento do jovem uma tensão Religião x "mundo". O que aconteceu foi uma troca de posicionamento cristão. O novo convertido, que era disputado por outras profissões de fé cristãs (Igreja Católica, Igreja Adventista do Sétimo Dia, Igreja Quadrangular), acabou optando por ficar na ADD, por vários motivos, entre eles os amigos e a possibilidade de receber os dons ${ }^{7}$ do Espírito Santo. A fé do jovem novo-convertido parece ter aumentado quando ele foi surpreendido por uma profecia que afirmava que um dia ele estaria dividindo o púlpito com o pastor.

\section{MOCIDADE EVANGÉLICA ASSEMBLEIANA: SUAS ESPACIALIDADES E SEUS MÚLTIPLOS SENTIDOS}

É o pensamento simbólico que supera a inércia natural do Homem e lhe confere
uma nova capacidade, a capacidade de reformular constantemente o seu universo humano.

(CASSIRER, 2005, p.104)

A capacidade de reformular o próprio universo humano está ligada à nossa capacidade de dar novos sentidos à mesma realidade material através da ação simbólica. Para Cassirer "a realidade física parece recuar em proporção ao avanço da atividade simbólica do Homem" (2005, p. 48). Múltiplos sentidos existem por trás de cada relato, de cada depoimento, de cada palavra. O que temos ao nosso alcance, partindo de um arcabouço teórico balizado pela filosofia das Formas Simbólicas, são interpretações que valorizam a conformação do mundo a partir da ação da Forma Simbólica Religião.

No mundo do jovem veterano, o sentido da religião nos parece pairar sobre a questão da paz. Religião aparece em sua vida no sentido de religare, isto é, religar o Homem a Deus. Nesse laço de união íntima com o Deus único, cabe ao ser humano servir e obedecer à vontade divina. Cria-se uma relação de dependência com a figura do criador. Nessa posição, a ordem posta é a paz mantida sob a condição de se aceitarem as regras, leis e mandamentos. Nessa perspectiva, para o jovem veterano, as leis não possuem um caráter repressor, mas antes libertador, pois é uma medida preventiva para que não haja possibilidade do "mal/satanás" (drogas, brigas, violência) voltar a fazer parte de sua vida, na qual agora impera o "bem/Jesus" (paz, amizades, música). Essa constatação nos induz a pensarmos em uma espacialidade do pensamento religioso extremamente adaptado à ideologia defendida pela Igreja.

O novo-convertido, por sua vez, se mostra um jovem em transição, buscando entender em que "mundo" está pisando. Compreende as potencialidades da religião e afirma querer desenvolvê-las a serviço de Deus. É um jovem marcado pela busca do

7 Essa é uma das principais características da Igreja Pentecostal, a crença nos dons do Espírito Santo. Os pentecostais defendem que os dons vão desde falar em línguas estranhas (glossolalia), falar em línguas que não conhecem (xenolalia), profetizar, interpretar sonhos, e até mesmo dom de cura para enfermidades que afligem o corpo. 
invisível, ele quer sentir e experienciar o transcendente, quer se entregar. Para esse jovem, em vez de religare, entendemos que o sentido de relegere (recolher-se, fazer uma nova escolha) é bem aplicado para a compreensão de sua jornada pelo sagrado. No depoimento do jovem, observamos diferentes Igrejas Cristãs disputando a sua atenção. Ele experimentou algumas delas, até chegar na ADD e fazer sua opção pelo religare.

Sua forma de ser nos leva a pensar em uma espacialidade intermediária, pois ela expressa uma passagem do aspecto místico (caráter mais expressivo, ligado as emoções) para o racional (caráter mais representativo, ligado a uma determinada ordem lógica) da religião. Sendo assim, nos parece que essa espacialidade se configura a partir da conversão do sujeito, é permeada pela configuração de um novo habitus de caráter religioso, a transformação não é apenas temporal, ela ocorre gradativamente nas espacialidades do sujeito. O novo-convertido passa a ter diante de si o desafio de reconstruir sua realidade edificando-a sobre um sólido campo simbólico onde a religião se enraíza. A solidez da ponte entre razão e emoção poderá indicar a direção que o levará a um desvio ou aprofundamento nesse mysterium fascinosum.

O espaço habitado pelo jovem veterano é plasmado de sentido pela Forma Simbólica Religião e manifesta uma realidade onde o importante é viver em paz, com a família e consigo mesmo, ainda que para isso tenha que manter distância do mundo considerado impuro e profano. É um espaço mentalmente delimitado (pela consciência do jovem sob à ação da Forma Simbólica Religião), onde é possível "estar livre", ou "preso por vontade própria". Podemos pensar, a partir daí, que esse jovem vive uma espécie de espacialidade resignada, formada por uma entrega ao universo religioso, uma submissão sem questionamentos, que reforça o discurso religioso para além da espacialidade concreta do templo. Uma espacialidade assim pensada pode ser expressa na busca desse jovem pelo sentimento de paz em sua vida, que exige dele uma manutenção constante de um religare que impõe a submissão a Deus e às autoridades religiosas. $\mathrm{O}$ mundo assim construído não significa infelicidade, é na sensação de paz e segurança oferecida pela religião que o jovem veterano se sente bem, conforme apontam suas palavras, "estando com Deus você tem aquela alegria, parece que não te falta nada. Deus como sendo o centro das coisas, você tendo ele no teu coração, o resto por si só já se completa." 8

E o jovem desviado? O jovem desviado é a expressão da rebeldia juvenil, do impulso dos hormônios que inundam a juventude e tomam a frente das faculdades cognitivas do ser. Ser um desviado da Igreja é declarar independência. E, por isso mesmo, arcar com suas ações e consequências. Em determinados momentos de sua vida, os ensinamentos aprendidos na Escola Dominical ficam em segundo plano. Os novos amigos e os novos espaços de sociabilidade vão abrindo caminho para o "mundo" e seus prazeres. Nesse instante onde a curiosidade fala mais alto que o raciocínio religioso, a Igreja perde o controle sobre o corpo ${ }^{9}$ dos moços e moças. Leis, tradições, mandamentos, tudo fica em um

8 Trecho da entrevista cedida pelo jovem veterano no dia 28/04/2011.

9 Uma escala em nível do corpo nos permite pensarmos o controle do corpo através do discurso religioso relacionando questões como aparência, comportamento e adoração. 1) Nas roupas, ornamentações e outros aspectos da aparência como um meio para o religioso expressar a si mesmo e sua fé. Funciona como fronteira que marca a alteridade em relação a outros 
plano obscuro e esquecido, pelo menos até o momento da excitação passar, e o desviado perceber que o seu caminho talvez não seja aquele. E entender que é a hora de pedir perdão e, mais uma vez, mergulhar na religião.

A espacialidade criada pela participação na esfera das coisas mundanas se entrelaça com a espacialidade criada pela religião. "Mesmo fazendo as coisas erradas e não merecendo, eu vou orar a Deus - me arranje um trabalho e tal pra mim que eu estou precisando"10, diz o jovem. Um duplo sentido parece imperar. Ao mesmo tempo em que há uma necessidade de estar apegado a Deus, exercendo sua religiosidade, existe certo prazer em manter-se no mundo, mesmo fazendo as coisas que são consideradas erradas pela ética evangélica. A distinção entre certo e errado está ainda vinculada à espacialidade do ethos religioso.

O desviado é também a expressão de uma nova forma de viver a religiosidade. Sua realidade parece estar plasmada de um duplo sentido, onde a ideia de "mundo", como foi pintada pela Igreja, convive com a religião e seu discurso. Dessa relação surgem conflitos e são gerenciados pelo sujeito que passa a vivenciar os dois universos simbólicos: a religião e o mundo laico. Talvez ele esteja na transição entre um religioso e alguém que "acredita em Deus, mas não tem religião".

Notamos que os conflitos existenciais vividos pelo jovem desviado podem ser expressos na ideia de espacialidade híbrida. O termo híbrido remete a uma mistura maleável, uma fusão entre dois elementos diferentes, neste caso o discurso religioso e a cultura juvenil representada pela ideia de "mundo". Conforma, assim, uma relação social e espacial onde elementos "mundanos" e religiosos se encontram e sua importância tem pesos diferentes dependendo da situação em que o sujeito se encontra. É uma espacialidade permeável, mais aberta a novas experiências. A Forma Simbólica Religião tem forte influência na ética do sujeito e também se apresenta com seus imperativos míticos. Essa relação de manter-se em uma linha fronteiriça entre universos simbólicos distintos configuram um peso de mea culpa (acionado pela Forma Simbólica Religião) que o sujeito acaba tendo que carregar, sendo esse o resultado de seus conflitos interiores. A espacialidade híbrida não é algo desejado pela Igreja para os seus jovens, no entanto, esse ponto parece ser um problema que pesa mais para a religião, pois para o jovem desviado essa é uma questão que ele busca negociar diretamente com Deus, ele é independente para escolher seus próprios caminhos, assim indicam suas palavras: “Deus está em primeiro plano na minha vida, uma hora ou outra eu volto, mas pelo menos agora eu vou curtir um pouco".

grupos. 2) Também pode revelar uma busca pela pureza pessoal. Além disso, 3) o corpo representa a mais imediata preocupação com as observâncias relacionadas a ortodoxia e ortopraxia (correções das deformidades do corpo [isso é visível pela busca da cura do corpo nos cultos pentecostais]). O controle do "espaço do corpo", "fornece meios fundamentais de promover acordos com expectativas do grupo relativo a aderência a leis religiosas ou o ethos de uma religião." Aspectos concernentes a adoração e expressão de fé individual também convergem para escala do corpo uma vez que orações, batismos, festas, para citar alguns exemplos, são manifestações explicitas de intersecções entre "espaço do corpo" e crença. Não podemos deixar de notar o uso de diferentes vestimentas relacionadas à posição no culto, pois o uso especial de indumentárias está ligado ao papel do corpo em rituais particulares. (STUMP, 2008, p. 240).

10 Trecho da entrevista cedida pelo jovem desviado no dia 30/04/2011. 


\section{CONSIDERAÇÕES FINAIS}

Acreditamos que na procura dos sentidos da juventude encontramos múltiplas juventudes buscando um sentido para vida. O espaço sagrado da Igreja Assembleia de Deus de Guarapuava (sede) se mostrou atraente para um público diverso, possivelmente pela sua localização central e sua postura mais liberal em relação aos templos da periferia da cidade. O discurso assembleiano é de caráter pentecostal, por essa razão encontramos nos cultos um espaço carregado de mística e fervor emocional, ainda que nem sempre com uma base intelectual mais consolidada. Suas Escolas Bíblicas e cursos teológicos visam preparar sua comunidade para estarem em "unidade simbólica", além de fornecerem o suporte racional para os fiéis sustentarem sua fé. Essa característica da Igreja é importante para entendermos os sentidos que são gerados pelo seu discurso, pois são nesses espaços de estudo onde o mundo assembleiano "feito de palavras" é apresentado enquanto um discurso estruturado e estruturante.

A religiosidade não é trabalhada da mesma forma por todos os membros da mocidade, existem aqueles que privilegiam a espacialidade social (lazer, diversão), outros a espacialidade do ethos (segurança, proteção). Conhecemos jovens com histórias surpreendentes, que através do sofrimento tornaram-se mais espiritualizados e com uma religiosidade mais desenvolvida. O convívio em grupo propicia que os/as diferentes jovens entrem em contato, se conheçam e aprendam um com o outro os mistérios da religião. A convivência é uma estrada de mão dupla, da mesma forma que possibilita a manutenção da fé, pode também levar aos desvios tanto por convites quanto por intrigas no grupo, algo comum quando se vive em sociedade.

Temos ainda as espacialidades que foram pensadas a partir da vivência de cada sujeito observado. Chegamos à espacialidade resignada (veterano), intermediária (novo-convertido) e híbrida (desviado). Essas espacialidades dizem respeito ao mundo simbólico que o sujeito habita, dependendo da posição dele dentro do universo religioso, uma dessas espacialidades é acionada. O que mantém tudo conectado é a partilha da linguagem expressa por uma visão de mundo conformada pela ação da Forma Simbólica Religião.

O que sugerimos, com a filosofia de Cassirer, é que as Formas Simbólicas atribuem novos sentidos para o mundo, dando a impressão para o sujeito que os vive que um novo espaço foi construído. Assim, a aplicação das verdades religiosas para a compreensão do mundo cria novos espaços e espacialidades, dando ao pesquisador a possibilidade de "geografizar" o mundo dos sentidos. Essa Geografia só é possível se levarmos em consideração que a articulação entre discurso religioso (universo simbólico) e mundo empírico (universo dos fatos) é feita através da ação das Formas Simbólicas.

Geografizar o mundo dos sentidos é buscar uma Geografia que parte de "dentro" para "fora" do sujeito, pois o ser humano aqui é entendido como um ser simbólico. Isso, pois entendemos que a fenomenologia de Cassirer é sua maior contribuição epistemológica para a ciência geográfica, uma leitura a partir dela sugere fazermos uma "revolução copernicana" (KANT, 1994) na Geografia, isto é, trocarmos do centro das análises o 
universo dos fatos pelo universo simbólico do "sujeito-objeto". Defendemos essa tese visto que entendemos que uma opção como essa é cara e valiosa para aqueles que se propõem a trabalhar com Geografia da Religião.

\section{REFERÊNCIAS}

ALVES, R. Religião e repressão. São Paulo: Teológica, Edições Loyola, 2005.

O que é religião. Vol. 5. São Paulo: Brasiliense, 1981.

BECKER, H. S. Métodos de pesquisa em ciências sociais. 4. ed. São Paulo: Hucitec, 1999.

BERGER, P.; LUCKMANN, T. A construção social da realidade: tratado da Sociologia do Conhecimento. 14. ed. Petrópolis: Vozes, 1997.

BOURDIEU, P. A Economia das Trocas Simbólicas. (Introdução, organização e seleção de Sérgio Miceli). São Paulo: Perspectiva, 1998.

CARRANO, P. C. R. A sociedade em redes. In: NOVAES, R.; PORTO, M.; HENRIQUE, R. Juventude, cultura e cidadania. Edição especial - 2002 - Ano 21. Comunicações do ISER. UNESCO: 2002.

CASSIRER, E. Filosofia das Formas Simbólicas I - A linguagem. São Paulo: Martins Fontes, 2001.

Linguagem e Mito. São Paulo: Perspectiva, 2006.

2005.

Ensaio sobre o Homem: introdução a uma filosofia da cultura humana. São Paulo: Martins Fontes,

FERNANDES, D. Juventudes e Religião: contribuições a partir da Geografia da Religião. In: I Seminário de Pesquisa Juventudes e Cidade, 01, 2011. (Digital) Anais... Juiz de Fora: Universidade Federal de Juiz de Fora, 2011.

Geografia da Religião: um olhar sobre as espacialidades da Assembleia de Deus. Dissertação (Mestrado em Geografia). Universidade Federal do Paraná. Curitiba: 2012. 130f.

GIL FILHO, S. F. Geografia da Religião: reconstruções teóricas sob o idealismo critico. In: KOZEL, S.; SILVA, J. da C.; GIL FILHO, S. F. (Orgs). Da Percepção e Cognição à Representação: reconstruções teóricas da Geografia Cultural e Humanista. São Paulo: Terceira Margem; Curitiba, NEER, 2007. p.207-222.

Espaço Sagrado: estudos em geografia da religião. Curitiba: Ibpex, 2008.

Da ontologia do sagrado de Rudolf Otto ao sagrado como Forma Simbólica. In: JUNQUEIRA, S. (Org) O Sagrado: fundamentos e conteúdo do ensino religioso. Curitiba: Ibpex, 2009. p.69-89.

Notas sobre a Religião como Forma Simbólica em Ernst Cassirer. Texto utilizado no encontro do NUPPER. Curitiba: 2010. (Não publicado)

Formas Simbólicas em Ernst Cassirer: ensaio para uma Geografia da Religião Compreensiva. In: Encontro Nacional da Associação Nacional de Pós-Graduação e Pesquisa em Geografia, 9, 2011. Anais... Goiânia: UFG, 2011. (CD-ROM)

JAPIASSÚ, H.; MARCONDES, D.; Dicionário básico de filosofia. 3 ed. Rio de Janeiro: Jorge Zahar, 1996.

KANT, I. Crítica da Razão Pura. Trad. Alex Marins. São Paulo: Martin Claret, 2001.

LIÇÕES BÍBLICAS. Edição do Aluno - jovens e adultos. CPAD: $1^{\circ}$ trimestre de 2011a.

Edição do Mestre - jovens e adultos. CPAD: $2^{\circ}$ trimestre de 2011b.

LÜDKE, M.; ANDRÉ, M.E.D.A. Métodos de coleta de dados: observação, entrevista e análise documental. In: LÜDKE, M.; ANDRÉ, M.E.D.A. Pesquisa em educação: abordagens qualitativas. São Paulo: EPU, 1986. p. 25-39. 
RENOVATO, E. Perigos da pós-modernidade. Rio de Janeiro: CPAD, 2007.

SILVA, A. S da; GIL FILHO, S. F. Geografia da Religião a partir das Formas Simbólicas em Ernst Cassirer: um estudo da Igreja Internacional da Graça de Deus no Brasil. REVER - Revista de Estudos da Religião. Junho, 2009. p. 73-91.

STUMP, R. W. The Geography of Religion: faith, place, and space. Lanham/ Boulder/ New York/ Toronto/ Plymouth: Rowman \& Littlefield Publishers, 2008.

TURRA NETO, N. Enterrado Vivo: identidade punk em Londrina. São Paulo, Editora UNESP, 2004.

. Observação participante como metodologia de pesquisa em Geografia Cultural. In: XIII Semana de Geografia: Paraná, 150 anos: Natureza e Formação Sócio-Espacial. Departamento de Geografia da Universidade Estadual do Centro-Oeste. Anais... Guarapuava: UNICENTRO, 2004b. p.81-95.

Múltiplas trajetórias juvenis em Guarapuava: territórios e redes de sociabilidade. 516 f. Tese (Doutorado em Geografia). Universidade Estadual Paulista, Faculdade de Ciências e Tecnologia, Presidente Prudente: 2008.

Recebido em 26-06-2014

Aceito para publicação em 31-07-2014 